space some six feet square of hard-beaten earth, with a post at each corner, was made ready for the preliminary curing of the leaf, a simple process of scorching the masses of verdure over burning logs.

Nearby, the barbacua was prepared, an arch of boughs supported on trestles; upon this arch the ilex leaves, now readily separated from large twigs and boughs, were placed for the secondary drying. The fire built below the arch was carefully tended to prevent the leaves from burning, and to ensure complete drying; and, when the process was complete, the barbacua and the ashes of the fire were removed, the ground swept and beaten smooth, and the dried ilex leaves placed on it, and pounded with wooden mallets.

The powdered or broken leaf was then packed tightly into sacks made from freshly flayed bulls' hides (serones), sewn up and left to dry. Each seron weighed 200-220 lb. when dry. A similar process is employed to-day.

(To be continued.)

\title{
Ascorbic Acid (Vitamin C)
}

THE discussion on ascorbio acid (vitamin $\mathrm{C}$ ) 1 which was held in Section B (Chemistry) at the recent meeting of the British Association was, as the official title of the discussion indicated, mainly devoted to the chemical aspect of the subject. Perhaps the chief impression brought away from the meeting was of the astonishing advance made in our knowledge of vitamin $\mathrm{C}$ since Tillmans and Hirsch in 1932, after discovering that the vitamin could undergo a reversible oxidation without loss of potency, pointed out the great similarity between its properties and those of Szent-Györgyi's hexuronic acid (now known as ascorbic acid) and suggested that the latter substance might itself be the vitamin.

The speedy confirmation of this suggestion by Szent-Györgyi himself, followed by many other workers, led to an intensive study of the chemistry of ascorbic acid, which resulted in the synthesis of the compound (1933) dowered with the full antiscorbutic potency of the natural substance. As has so often happened, it has also led to the synthetic production of numerous substances of similar composition, none of which has so far been found in plants or animals, but some of which are possessed of substantial antiscorbutic power, in all cases up to the present considerably less than that of ascorbic acid itself. A new chapter in the study of the relations between physiological properties and chemical constitution has thus been opened and many interesting results have already been obtained.

Conflicting results were obtained by different investigators as to the constitution of ascorbic aeid, but further experience has decided in favour of that worked out by Dr. E. L. Hirst and his colleagues at the University of Birmingham as against that of the Swiss workers Micheel and Kraft. Nevertheless, both formulæ served to inspire the successful synthesis of the acid, which was independently effected by the same method at Birmingham (Haworth and colleagues) and at Zurich (Reichstein and colleagues) - not the first occasion, as Dr. Reichstein remarked, on which synthetic studies, though based on incorrect suppositions, have turned out successfully.

The original synthesis from $l$-xylosone by way of the hydroxynitrile

$$
\begin{aligned}
& \mathrm{CH}_{2} . \mathrm{OH} . \mathrm{CH}(\mathrm{OH}) . \mathrm{CH}(\mathrm{OH}) . \mathrm{CO} \cdot \mathrm{CHO} \longrightarrow \longrightarrow \\
& \mathrm{CH}_{2} . \mathrm{OH} . \mathrm{CH}(\mathrm{OH}) . \mathrm{CH}<\begin{array}{c}
\mathrm{O}-\mathrm{CO}_{\mathrm{C}}(\mathrm{OH}): \mathrm{C}(\mathrm{OH}) \\
<
\end{array}
\end{aligned}
$$

suffers from the disadvantage that the raw material of the synthesis is difficult to prepare in quantity. It is, however, a general method and can be applied to other osones, leading to the production of the corresponding 'ascorbic acids'. Among the results which followed rapidly on the synthesis of $l$-ascorbic acid were the preparation. of $d$-ascorbic acid, from $d$-xylosone, and of the corresponding products from the arabinosones, $d$-arabo-ascorbic acid and $l$-arabo-ascorbic acid. Of these four isomerides, $l$-ascorbic acid has the full antiscorbutic potency of the natural acid; $d$-ascorbic acid is quite inactive, so far as it has been tested; $d$-arabo-ascorbic acid possesses about one twentieth of the activity of $l$-ascorbic acid and $l$-arabo-ascorbic acid is quite inactive. $l$-Rhamno-ascorbic acid, prepared from rhamnosone (Reichstein) has about one fifth of the activity of $l$-ascorbic acid, the highest value yet found in any analogue of the natural acid.

The osones of the hexoses yield the corresponding 'ascorbic acids' containing seven carbon atoms. The derivatives of $d$-glucosone and $d$-galactosone are inactive, whilst that of $l$-glucosone has a slight activity, about one fortieth of that of the natural acid.

The tentative conclusion drawn from the data so far available is that the antiscorbutic activity of the substance is, in the first instance, correlated with the configuration of the fourth carbon atom, which in $l$-ascorbic acid is the optically active carbon atom of the ring. If the configuration about this carbon atom is dextro, as in $l$-ascorbic acid, the substance possesses anti- 
scorbutic power; if the configuration is laevo, the substance is inactive (Reichstein). Haworth has also directed attention to the fact that the formulæ of $l$-ascorbic acid and $d$-arabo-ascorbic acid are identical with respect to the stereochemical arrangement of groups attached to the ring and only differ by the reversal of one $\mathrm{OH}$-group in the side chain. The remaining part of the molecule, however, has a considerable effect on the degree of antiscorbutic power of the substance, as is shown by the great difference between the two compounds just referred to in this respect, the potency of $d$-arabo-ascorbic acid being only one twentieth of that of $l$-ascorbic acid.

The following formulæ illustrate these points. It has been assumed that the constitution of the ring is the same in all these substances, although this has not yet been proved in each case.

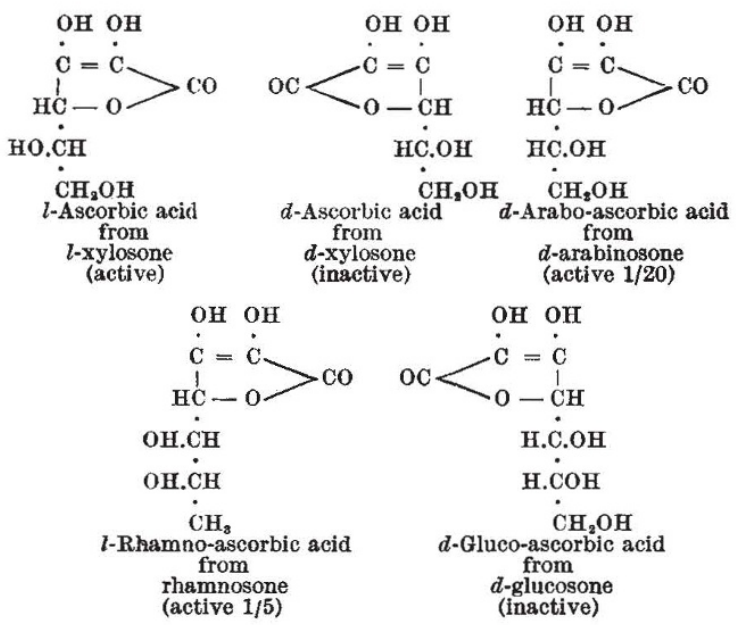

An alternative mode of synthesis of compounds of this class has been found, again by both groups of workers, which has the advantage that the raw material is easier to prepare. This process consists in the oxidation of the $\beta$-ketoses to form $\beta$-ketonic acids, the osonic acids, which readily undergo isomerisation to the corresponding ascorbic acid derivatives. For example, in the case of sorbose, we have the following changes:

$$
\begin{gathered}
\mathrm{CH}_{2}(\mathrm{OH}) \cdot \mathrm{CH}(\mathrm{OH}) \cdot \mathrm{CH}(\mathrm{OH}) \cdot \mathrm{CH}(\mathrm{OH}) \cdot \mathrm{CO} \cdot \mathrm{CH}_{2} \mathrm{OH} \\
\mathrm{CH}_{2}(\mathrm{OH}) \cdot \mathrm{CH}(\mathrm{OH}) \cdot \mathrm{CH}(\mathrm{OH}) \cdot \mathrm{CH}(\mathrm{OH}) \cdot \mathrm{CO} \cdot \mathrm{COOH} \longrightarrow \\
\mathrm{CH}_{2}(\mathrm{OH}) \cdot \mathrm{CH}(\mathrm{OH}) \cdot \mathrm{CH}<-\mathrm{O}-\mathrm{CO} \\
\mathrm{C}(\mathrm{OH}): \mathrm{C}(\mathrm{OH})
\end{gathered}
$$

In addition to opening up a new method for the preparation of further members of the ascorbic acid series, this synthesis has provided a rapid and cheap method for the production of $l$-ascorbic acid. Glucose is reduced to sorbitol and the latter oxidised to sorbose by Bertrand's method, making use of the action of an appropriate oxidising bacterium. The sorbose is then oxidised directly by means of dilute nitric acid (Haworth) or, in the form of its di-acetone compound, by perman. ganate (Reichstein) and the product is isomerised by heating with water. So efficacious is the method that the synthetic acid is at present attainable at a cost less than that of sufficient oranges to contain the quantity purchased.

Turning now to the biological function of ascorbic acid, it is to be noted that the fundamental problem of the part which it plays in normal metabolism has not yet been solved. Szent-Györgyi attributes its physiological properties to its high reducing power and the reversible nature of its oxidation. Preliminary observations suggest that it may be a useful remedy in several diseases which have hitherto not been found amenable to medical treatment. Among these Szent-Györgyi mentions purpura hæmorrhagica, Werlhoff's disease, certain forms of hæmorrhagica nephritis and hæmophilia, pyorrhea, etc. Protection against disease appears to depend on the level of content of the vitamin in the organism, and the curative effects so far observed suggest that humanity is suffering more gravely from a lack of vitamin $\mathrm{C}$ than has hitherto been supposed.

Another interesting fact mentioned by SzentGyörgyi is the effect of the vitamin on pathological pigmentation. Whereas it has no effect on normal pigmentation, its administration is stated to cause the disappearance of the pathological pigmentation which accompanies certain diseases, such for example as Addison's disease.

Until the clinical evidence is available, these claims must be considered as being sub judice, but the suggestion that ascorbic acid is capable of producing such effects will arouse great interest and no doubt will lead to a thorough investigation of the subject, in the course of which it is to be expected that some light will be thrown on the part played by ascorbic acid in the normal metabolism both of plants and animals.

Szent-Györgyi also suggested that only animals living normally under tropical conditions require a supply of ascorbic acid from external sources. The animals of our temperate zone-the dog, the rat, the fowl, etc.-are capable of synthesising the vitamin, whereas the guinea pig and the monkey require a constant supply in their diet. Man belongs to the latter group, and the suggestion is made that this points to some tropical region as the birthplace of mankind.

It will be seen that great progress has been made in the study of vitamin $\mathrm{C}$, and the plentiful supply of the pure material which is now assured justifies us in looking forward to further advances in the near future, which can scarcely fail to provide the clue to the metabolic function of this vitamin in particular and to add greatly to our knowledge of metabolism in general. A. H. 